\title{
Redesigning the advanced pharmacy practice experiential education from hospital to home: A COVID-19 scenario
}

\author{
Jisha Myalil Lucca ${ }^{1}$, Dana Muwafag Alsugeir ${ }^{1}$ (D), Bashayer Mohmmed Al Shehail ${ }^{2}$, Veerendra Chandralla ${ }^{1}$ (D), \\ Dhafer Mahdi Alshayban ${ }^{1}$, Hisham Bukhamseen ${ }^{3}$ \\ ${ }^{1}$ Department of Pharmacy Practice, College of Clinical Pharmacy, Imam Abdulrahman Bin Faisal University, Saudi Arabia \\ ${ }^{2}$ Department of Pharmacy, King Fahad University Hospital, Khobar, Saudi Arabia \\ ${ }^{3}$ Department of Pharmacy, King Fahad Specialist Hospital, Dammam, Saudi Arabia
}

\section{Keywords}

Pharmacy Education

Distant Learning

Advanced Pharmacy Practice Experience COVID-19

Training

Pharmacy Internship

Remote Learning

Virtual Rotation

\section{Correspondence}

Dana Alsugeir

Department of Pharmacy Practice

College of Clinical Pharmacy

Imam Abdulrahman Bin Faisal University

P.O. Box 34212

Dammam

Saudi Arabia

dmalsugeir@iau.edu.sa

\begin{abstract}
Introduction: During the 2020 COVID-19 pandemic, suspension of many educational activities occurred to mitigate the risks of infection spread. For pharmacy students in their internship year, many efforts have been made to move their experiential training to a virtual platform without compromising learning outcomes. Objectives: Redesign the advanced pharmacy practice experience (APPE) to remote learning without compromising the learning outcomes; Develop an appropriate teaching modality/strategy and assessment method for remote APPE; To drive the change in experiential education by providing guidance for other pharmacy schools dealing with similar situations. Restructured APPE: Eighty-seven interns were switched to an online internship with five specialties based on the availability of the preceptors, namely internal medicine, infectious diseases, oncology, total parenteral nutrition, and psychiatry. Experiential education activities such as drug information questions, case presentations, and clinical pharmacy topic discussions took place on virtual platforms. Student assessment was done using adjusted rubrics to suit the online platforms. Student feedback was taken using an online questionnaire and was mostly positive, indicating that they improved their clinical pharmacy knowledge. Conclusion: The authors highlighted the various restructuring modalities and learning methods used for different clinical rotations to achieve the learning outcomes in difficult situations. In future, the authors plan to work with their colleagues in other health colleges to adapt their practices together.
\end{abstract}

\section{Introduction}

Pharmacy workforce and pharmacy education in Saudi Arabia have grown quickly over the last decade (Almaghaslah et al., 2019). Correspondingly, an increase was observed in the number of pharmacy schools. There was only one school in 2000, 18 in 2010, and now, 30 in 2020 (AlRuthia et al., 2018). The majority of pharmacy colleges in Saudi Arabia offer the Doctor of Pharmacy (Pharm.D.) to ensure that Saudi pharmacy graduates are equivalent to those graduating from the pharmacy schools in more developed countries. Hence, pharmacy schools in the kingdom prefer a Pharm.D. curriculum that aligns with the programmes of pharmacy schools in the USA and Canada (Asiri, 2011; Dutta, 2005). The USA Accreditation Council for Pharmacy Education (ACPE) state that upon completion, the pharmacy students need to be competent to practice independently and to ensure optimal pharmaceutical care outcomes (American Council 
for Pharmacy Education, 2016). Therefore, Imam Abdulrahman Bin Faisal's Pharmacy College considers Advanced Pharmacy Practice Experience (APPE) rotations as an integral part of shaping and strengthening the Pharm.D. Programme. This supports the students to develop self-confidence, proficiency, and independent practice and gives each student various opportunities to conduct major patient care duties in different clinical practice settings (Asiri, 2011).

The first confirmed case of COVID-19 in Saudi Arabia was reported on March $2^{\text {nd }} 2020$ (Barry et al., 2020). On the $8^{\text {th }}$ of March, the Ministry of Education announced that public and private schools, as well as universities, would be closed (Dutton, 2020). As part of precautionary measures, curfews were imposed all over the kingdom which had an adverse impact on all sectors, including teaching and training activities at schools, colleges, and hospitals. Correspondingly, all educational institutions started to rely on online resources to deliver their coursework (Kawaguchi-Suzuki et al., 2020). To avoid the long interruption in APPE rotations and to ensure students will graduate on time, the IAU college of pharmacy training committee decided to start virtual internships by using online platforms via video streaming solutions. In this paper, the authors present their experience of restructuring APPE rotation from hospital to home to avoid the risk of exposure to COVID-19.

\section{Objectives}

- Redesign the APPE to remote learning without compromising the learning outcomes;

- Develop appropriate teaching modality/strategy and assessment method for distant APPE;

- To drive the change in experiential education by providing guidance for other pharmacy schools dealing with this global pandemic.

\section{Programme description}

Imam Abdulrahman Bin Faisal University (IAU) is a governmental institution located in Dammam, Saudi Arabia. Its School of Clinical Pharmacy offers a six-year full-time Pharm.D. programme including one year of APPE hospital rotations which consists of seven core and three elective rotations (IAU, 2020). Each rotation is five weeks long. All course learning outcomes are structured as per the Saudi National Commission for Academic Accreditation \& Assessment (NCAAA) standards (Education \& Training Evaluation Commission, 2018). The pharmacy interns are allocated to 20-25 affiliated training sites to accomplish their APPE rotations under the supervision of well-trained clinical preceptors. The training sites vary between governmental or private hospitals, regulatory organisations, and pharmaceutical companies. The intern-preceptor ratio ranges from 1:1-3. APPE rotations in the college of clinical pharmacy are under the supervision of the Vice-Dean of research and training and the Experiential Educational Committee, consisting of two professors from the pharmacy practice department, clinical preceptors, and teaching assistants (TA).

\section{Challenges}

The interns had completed an average of seven APPE rotations before the pandemic. They lost approximately three weeks of their ongoing rotations due to the suspension of students at affiliated hospitals and some zones of the country being under confinement. Interns were expected to complete their APPE rotations by the end of July 2020. Therefore, the first challenge was the effective utilisation of time, in particular the requirement for interns to complete 160 hours of supervised practice under each speciality. Secondly, the majority of preceptors in the hospitals were busy managing the additional hospital workload due to the pandemic. Similarly, few of them were familiar with remote education and consequently, a large number of students had to be distributed among limited preceptors. Lastly, a limited number of interns may have had to move to a rotation they had already repeated.

\section{Proposed scheme}

Without affecting the integrity of learning outcomes and achievements, a virtual experiential education strategy was proposed, based on a backward design method. Here, the authors define the learning objectives, decide on the acceptable methods for measuring the learning outcomes and develop the learning experience. The majority of rotation-specific clinical activities was placed under one of four NCAAA domains, namely knowledge, cognitive skills, interpersonal and responsibility skills, and communication skills (Table 1) (Education \& Training Evaluation Commission, 2018). A holistic assessment method, concentrating on continual quality improvement, was also considered. Activities that expand the students' clinical skills and critical thinking were developed and executed. Both synchronous (video conferencing, live chat) and asynchronous online methods (e-mail, videos, discussion forum) for learning were adopted. 
Table I: Proposed plan for virtual internships

\begin{tabular}{|c|c|c|c|}
\hline $\begin{array}{l}\text { Learning } \\
\text { domains }\end{array}$ & $\begin{array}{l}\text { Teaching } \\
\text { modality }\end{array}$ & $\begin{array}{l}\text { Teaching } \\
\text { strategies }\end{array}$ & $\begin{array}{l}\text { Assessment } \\
\text { methods }\end{array}$ \\
\hline Knowledge & $\begin{array}{l}\text { Online video } \\
\text { interactions } \\
\text { Reading } \\
\text { Simulated } \\
\text { videos } \\
\text { Shared folders } \\
\text { E-mails }\end{array}$ & $\begin{array}{l}\text { Short group } \\
\text { discussion } \\
\text { Large group } \\
\text { lecture } \\
\text { Brainstorming } \\
\text { Case discussion } \\
\text { and } \\
\text { presentation } \\
\text { Journal club }\end{array}$ & $\begin{array}{l}\text { Rubrics } \\
\text { Assignments } \\
\text { Portfolio or end } \\
\text { rotation } \\
\text { documentation } \\
\text { Short questions } \\
\text { (Viva) }\end{array}$ \\
\hline $\begin{array}{l}\text { Cognitive } \\
\text { skills }\end{array}$ & $\begin{array}{l}\text { Online video } \\
\text { interactions } \\
\text { Simulated } \\
\text { videos } \\
\text { Simulated } \\
\text { patient }\end{array}$ & $\begin{array}{l}\text { Case discussion } \\
\text { and } \\
\text { presentation } \\
\text { Journal club }\end{array}$ & $\begin{array}{l}\text { Problem solving } \\
\text { exercises } \\
\text { Rubrics }\end{array}$ \\
\hline $\begin{array}{l}\text { Interpersonal } \\
\text { skills \& } \\
\text { responsibility }\end{array}$ & $\begin{array}{l}\text { Online video } \\
\text { conference }\end{array}$ & $\begin{array}{l}\text { Verbal } \\
\text { instructions } \\
\text { Group } \\
\text { discussion } \\
\text { Immediate } \\
\text { feedback }\end{array}$ & $\begin{array}{l}\text { Performance level } \\
\text { rubrics } \\
\text { Observation } \\
\text { (participation) }\end{array}$ \\
\hline $\begin{array}{l}\text { Communicati } \\
\text { on Skills }\end{array}$ & $\begin{array}{l}\text { Simulated } \\
\text { patient } \\
\text { Online video } \\
\text { interaction }\end{array}$ & $\begin{array}{l}\text { Patient } \\
\text { counselling } \\
\text { Medication } \\
\text { history }\end{array}$ & $\begin{array}{l}\text { Rubric } \\
\text { Performance level } \\
\text { rubrics } \\
\text { (Viva) }\end{array}$ \\
\hline
\end{tabular}

\section{Virtual internship pre-rotation activity}

Eighty-seven interns were given the opportunity to select a virtual internship. Once assigned the APPE, interns received an introduction by the Vice-Dean for Training and Research who described the purpose of overall activities of the virtual rotation and ensured the students completely understood their responsibilities. All students were asked to revise the rotation-specific knowledge by undertaking the recommended readings mentioned in the training manual. Likewise, interns were asked to communicate with their peers who had completed the specific rotations before COVID-19. For example, units like psychiatry have a rotation-specific manual, comprised of a rotation description, goals and objectives, activities involved, topics for discussion, and references. This enables students to understand how they are supposed to perform under each rotation- specific activity in the units.

\section{Restructuring the APPE rotation}

The online internship commenced with five specialties based on the availability of the preceptors, namely internal medicine, infectious diseases, oncology, total parenteral nutrition (TPN), and psychiatry. Two teaching assistants (Pharm.D. graduates with experience in APPE rotations) were assigned to each preceptor to facilitate the rotations. A student leader was nominated from the respective rotation to facilitate telecommunication An 'APPE Virtual internship' team was launched, including the Vice-Dean of Training, members of the Experiential Education Committee, preceptors, and TAs involved in remote APPE as well as both male and female student leaders.

An internship programme should enhance students' learning experiences by developing competencies and skills necessary for them to become highly functional, competent pharmacists. Interns should participate in a comprehensive patient care delivery experience, understanding the importance of each step along the way. Therefore, recommencing all possible clinical activities, excepting the ward round participation at this critical time, was endorsed. To complete this, various online communication forms like office chatting, video conferences, simulated videos and patients (preceptors acted as simulated patients), file sharing and storage were used for communication.

Each specific rotation was planned to achieve the NCAAA's four domains (Education \& Training Evaluation Commission, 2018). During the first day of the week, activities were included to assess the knowledge domains such as topic presentation and discussion. The remaining days focused on communication skills and cognitive skills through various clinical activities like the medication history interview and patient counselling, drug information, and creating a therapeutic plan for both real and hypothetical cases (Table II).

\section{Case presentation}

Case presentation is an interactive, student-centred exploration of a realistic or specific narrative that provides useful materials and support for inductive learning. The students are asked to solve questions that have no single answer. This fosters critical thinking, encourages responsibility, and transfers information, concepts, and technique into practice. Similarly, it enables the interns to use self-questioning and self-directed learning. A hypothetical case, case bank (cases available to the preceptors based on previous experience), or simulated patient (preceptor as a simulated patient) was broadcasted to students via different online resources. The presentation was either synchronised or asynchronised, based on the speciality of rotations.

\section{Topic discussions}

Preceptors scheduled meetings for the discussion of various topics with students. Background readings were 
Table II: Restructured APPE

\begin{tabular}{|c|c|c|c|c|}
\hline Day & Clinical activity & Methods & Online tool & Time \\
\hline \multirow[t]{3}{*}{ Sunday } & Introduction to rotation & $\begin{array}{l}\text { Short lecture and large group discussion } \\
\text { Reading }\end{array}$ & Zoom/shared folders & 08.00 - 09.50 a.m. \\
\hline & Topic discussion and presentation & $\begin{array}{l}\text { Brainstorming, reading, and short group } \\
\text { discussion }\end{array}$ & Zoom & 10.00 - 11.50 a.m. \\
\hline & Drug information question & Short group discussion & MS Office/Zoom & 01.00 - 3.00 p.m. \\
\hline \multirow[t]{3}{*}{ Monday } & Case discussion & $\begin{array}{l}\text { Short group discussion } \\
\text { Hypothetical case } \\
\text { Video }\end{array}$ & Zoom/MS office & 08.00 - 09.50 a.m. \\
\hline & Treatment chart review & Short group discussion & $\begin{array}{l}\text { Remote access to the hospital } \\
\text { system }\end{array}$ & 10.00 - 11.50 a.m. \\
\hline & Medication history interview & Video and reflexion & $\begin{array}{l}\text { Simulated video/social media } \\
\text { platform/Medscape/YouTube }\end{array}$ & 01.00 - 3.00 p.m. \\
\hline \multirow[t]{3}{*}{ Tuesday } & Case discussion & $\begin{array}{l}\text { Short group discussion } \\
\text { Hypothetical case } \\
\text { Video }\end{array}$ & Zoom/MS office & 08.00 - 09.50 a.m. \\
\hline & Rotation-specific activity & Short group discussion & Zoom/MS office & 10.00 - 11.50 a.m. \\
\hline & Assignment & Short group discussion & Zoom & 01.00 - 3.00 p.m. \\
\hline \multirow[t]{3}{*}{ Wednesday } & Patient counselling & $\begin{array}{l}\text { Video and reflexion } \\
\text { Simulated patient }\end{array}$ & $\begin{array}{l}\text { Simulated video/social media } \\
\text { platform }\end{array}$ & 08.00 - 09.50 a.m. \\
\hline & Journal club & Short group discussion & Zoom/MS office & 12.00 p.m. \\
\hline & Rotation-specific activity & Short group discussion & Zoom/MS office & 03.00 p.m. \\
\hline \multirow[t]{3}{*}{ Thursday } & Case presentation & Simulated patient & Zoom & 08.00 - 09.50 a.m. \\
\hline & Rotation-specific activity & Short group discussion & Shared folders & 12.00 p.m. \\
\hline & Short questions (Viva) & & Zoom/MS office & $01.00-03.00$ p.m. \\
\hline
\end{tabular}

provided when available (some suggested readings listed with topics in this section). Brainstorming sessions were carried out before each topic discussion. Topic discussions were conducted in small groups of five to six students, and large group discussions consisted on average of ten to 15 students.

\section{Journal club}

At present, journal club is considered as the most common tool in almost all educational programmes. During the APPE, journal club enhanced the interns' literature-evaluation skills with clinical expertise, relating published literature to clinical practice to draw conclusions. Hence, it was sensible to resume the journal club in a similar style as before the COVID-19 pandemic. A topic was announced by the preceptor and small group discussions were then carried out under the supervision of TAs, followed by a large group presentation.

\section{Treatment chart review}

A treatment chart review enables the interns to define errors in the ordering, recording, distributing, administering, and monitoring of medication. Moreover, it enables the interns to identify potential adverse reactions and drug interactions. During the virtual internship, a retrospective chart review was made by using remote access to the hospital system. Since one of the rotation sites was the university hospital, the preceptors made a special request to acquire remote access to the hospital database 'QudraMed'. The preceptors made the screens available for students and a live session was created to simulate the hospital chart review. Later, a discussion was carried out about the identified medication related problems.

\section{Medication history interview}

Taking an accurate medication history is crucial in the pharmaceutical care process for the early detection and management of adverse drug reactions, drug interactions, and medication adherence. A virtual case was provided to the students by using free online resources such as YouTube and Medscape. Later, students were asked to create a reflection of this audiovisual, followed by a small group discussion or debate on these reflections.

\section{Rotation-specific activity}

In order to achieve the rotation-specific goals, besides the general activities mentioned in Table II, APPE students undertook several rotation-specific activities (Table III). The authors ensured that all rotation-specific activities also met the four domains of NCAAA. In psychiatry, students were asked to involve the MSE interpretation 
and medication adherence improving strategies. In oncology, students participated in writing a pharmacotherapy care plan, using five-point evidence blocks. In the infectious disease rotation, APPE students were provided with additional two weeks of training to learn more about the current COVID-19 pandemic. Here, the authors focused on evidence-based care for COVID-19 patients. Focus group discussions included the screening, prevention, manage- ment, and psychological aspects of the COVID-19 pandemic on the role of pharmacists. In order to mimic hospital experience, the authors prepared three interactive COVID-19 cases in which students applied the knowledge gained during the two weeks of developing a pharmacotherapy plan. The cases differed in severity and approach, including two critically ill patients and one with moderate severity. The approach was based on the latest available evidence and gave students the chance to see first-hand the role of pharmacists in caring for these patients. The focus was on tailoring a regimen, adjusting the doses, discussing possible drug-drug interaction, and when to use each agent based on severity and patient scenario. Training in TPN covered designing parenteral nutrition formulation and guidelines for safe preparation, administration of parenteral nutrition, and preventing and treating nutrition support complications. Internal medicine focused on practice-related issues such as TDM of anti-epileptic drugs, in-hospital management of hyperglycemia, atrial fibrillation, and anticoagulation issues.

To emphasis the significance of pharmacists' responsibilities in emergencies or disaster management, an additional two weeks were provided for COVID-19 specific topics. This rotation enabled interns to understand the integral role of pharmacists in delivering evidence-based care for a life-threatening pandemic like COVID-19, where a definitive treatment is unavailable. Topics are framed according to the updated day-to-day COVID-19 treatment strategies. Likewise, to raise the awareness of APPE interns for the screening of mental health problems and to develop their social commitments, additional topics such as substance abuse during COVID-19 and the role of pharmacists in the management of PTSD have been considered.

\section{Contact hours of APPE virtual rotation}

During the COVID-19 pandemic, APPE students were provided with an average of four to five hours of activity with their supervisor and TA. Similarly, at the end of each meeting, interns had about three hours of allotted readings, assignments, and activities to complete before the next session on the following day. During the weekends, interns had nearly four to five hours of additional assignments and activities to finish. Therefore, on average, APPE students had a total of 45 hours of internship experience for fulfilling the rotation requirements. This is similar to the regular internship rotation contact hours.

\section{Assessment}

In any learner-centred programme, continuous quality improvement is mandatory. The preceptors evaluated the students daily via videoconference sessions, based on achievements of the predefined goals and objectives for a respective rotation. During the assessment, interns were evaluated based on their interactions with preceptors, TA, through the daily discussions with the preceptor concerning patient care. The authors decided to continue the same assessment methods that were used before virtual internships, by excluding the midpoint evaluation rubrics. Therefore, the mid-point evaluation was made through either Viva/short questions or short problemsolving exercises. The preceptors completed the final written evaluation at the end of the rotation, according to School of Pharmacy criteria that were set before COVID-19. The same rubrics of case presentation, journal club, and the performance level were used by excluding some criteria. For a more precise assessment, additional assignments were considered during the virtual internships. At the completion of their internship, APPE interns were asked to submit a complete portfolio.

\section{Students' feedback}

An online survey was sent to all interns after completing the restructured virtual APPE. All 87 students who took the virtual internship viewed the survey, 67 started, and only 48 (55\%) completed the survey. The survey consisted of six Likert-scale questions and three open comment questions. Of the 48 who completed the survey, around $56 \%(n=27)$ of the interns agreed or strongly agreed that the restructured APPE allowed them to achieve specific learning outcomes. In addition, most students ( $n=28$, $58 \%$ ) agreed that the length of the rotation was appropriate. A total of 38 interns (80\%) agreed that the content was communicated clearly. Overall satisfaction with the virtual training was achieved by $58 \%$ of interns, likewise, $52 \%$ of them reported that the virtual internship met their expectations. Virtual case presentation (87\%) and journal club (85\%) were the most favoured aspects of the virtual internship by the interns. Likewise, $85 \%$ of the students stated that an approximate of $85-95 \%$ of the clinical skills were achieved through virtual internships during this global pandemic. 
Table III: Rotation-specific activities

\begin{tabular}{|c|c|}
\hline Rotation & Clinical activity specific to rotation \\
\hline Psychiatry & $\begin{array}{l}\text { Performing TDM for patients } \\
\text { Faculty preceptors provided the APPE students with a made-up or anonymous patient case with the relevant information needed for writing a } \\
\text { TDM note } \\
\text { - Preceptors provided the APPE students with a hypothetical case; relevant information needed to write on TDM interpretation of mood } \\
\text { stabilisers such as the reason for low or high level. Interventions to be taken for correction of the same } \\
\text { How to interpret MSE } \\
\text { - Preceptors provided the interns with a simulated video from a free online platform, students were later asked to write a reflection on the } \\
\text { video } \\
\text { - Explain the importance of MSE for pharmacists } \\
\text { Scales for detection of adverse drug reactions in psychiatry } \\
\text { - An assignment was given to the students regarding scales used in psychiatry, they were asked to present a power point presentation in two } \\
\text { groups, later a debate between these groups was conducted } \\
\text { Medication adherence in psychiatry } \\
\text { - Mock case discussions were held to identify the barriers and reasons for medication adherence } \\
\text { Substance abuse } \\
\text { - A small group discussion was conducted on substance abuse issues and the role of pharmacists in managing substance abuse }\end{array}$ \\
\hline $\begin{array}{l}\text { Infectious } \\
\text { disease (ID) }\end{array}$ & $\begin{array}{l}\text { Management strategy for MRSA bacteria } \\
\text { A real case with MRSA bacteraemia was given to students, requiring them to recommend first-line management, a discussion was held and later } \\
\text { the information was conveyed to the ID team } \\
\text { Performing TDM for patients } \\
\text { - Preceptors provide the students with a hypothetical case and relevant information needed to discuss TDM interpretation for Vancomycin } \\
\text { and Aminoglycoside } \\
\text { Principles of the antibiotic stewardship programme (ASP) } \\
\text { - A large group discussion was held on different media of cultures, staining methods, and interpretation of sensitivity testing } \\
\text { - A formulary management exercise was provided, focusing on empirical antibiotic therapy approaches and de-escalation principles } \\
\text { - A mock case discussion was conducted on antimicrobial regimen tailoring, based on the agent coverage, pharmacokinetic consideration, and } \\
\text { penetration } \\
\text { Role of pharmacists in managing covID-19 } \\
\text { - The journal club was conducted on a meta-analysis on modes of transmission of COVID-19 by a group of interns } \\
\text { - Literature reviews were conducted on available guidelines and evidence related to COVID-19 } \\
\text { - Large group discussions were conducted on the management of suspected and confirmed cases of COVID-19 } \\
\text { - Case presentation was carried out on a hospitalised case of moderate and severe critically ill COVID-19 } \\
\text { - A discussion group was conducted on updated on vaccines in the pipeline for the novel disease } \\
\text { - Part of the COVID-19 IVIG usage protocol } \\
\text { - An assignment was submitted on the role of antithrombotics in COVID-19 } \\
\text { - An assignment was submitted on pharmaceutical care services of a COVID-19 positive psychiatric patient } \\
\text { - A lecture was delivered on the role of pharmacists in prevention of substance abuse during COVID-19 } \\
\text { - A discussion forum was hold on the role of pharmacists in management of post-traumatic stress disorders during COVID-19 }\end{array}$ \\
\hline Oncology & $\begin{array}{l}\text { Interpretation and application of guidelines in oncology cases } \\
\text { - A hypothetical case of breast and prostate cancer was presented to the interns and they were asked to do a pharmacist assessment based on } \\
\text { the provided subjective and objective data and to provide an appropriate first-line treatment plan by interpreting the available oncology } \\
\text { clinical guidelines } \\
\text { Assessment of evidences by using five points evidence blocks in oncology } \\
\text { - Once interns provided the first-line treatment plan for the hypothetical cases, they were asked to grade the evidences regarding the efficacy, } \\
\text { safety, quality of evidence, consistency of evidence, and affordability of regimen }\end{array}$ \\
\hline
\end{tabular}


Table III: Rotation-specific activities (continued)

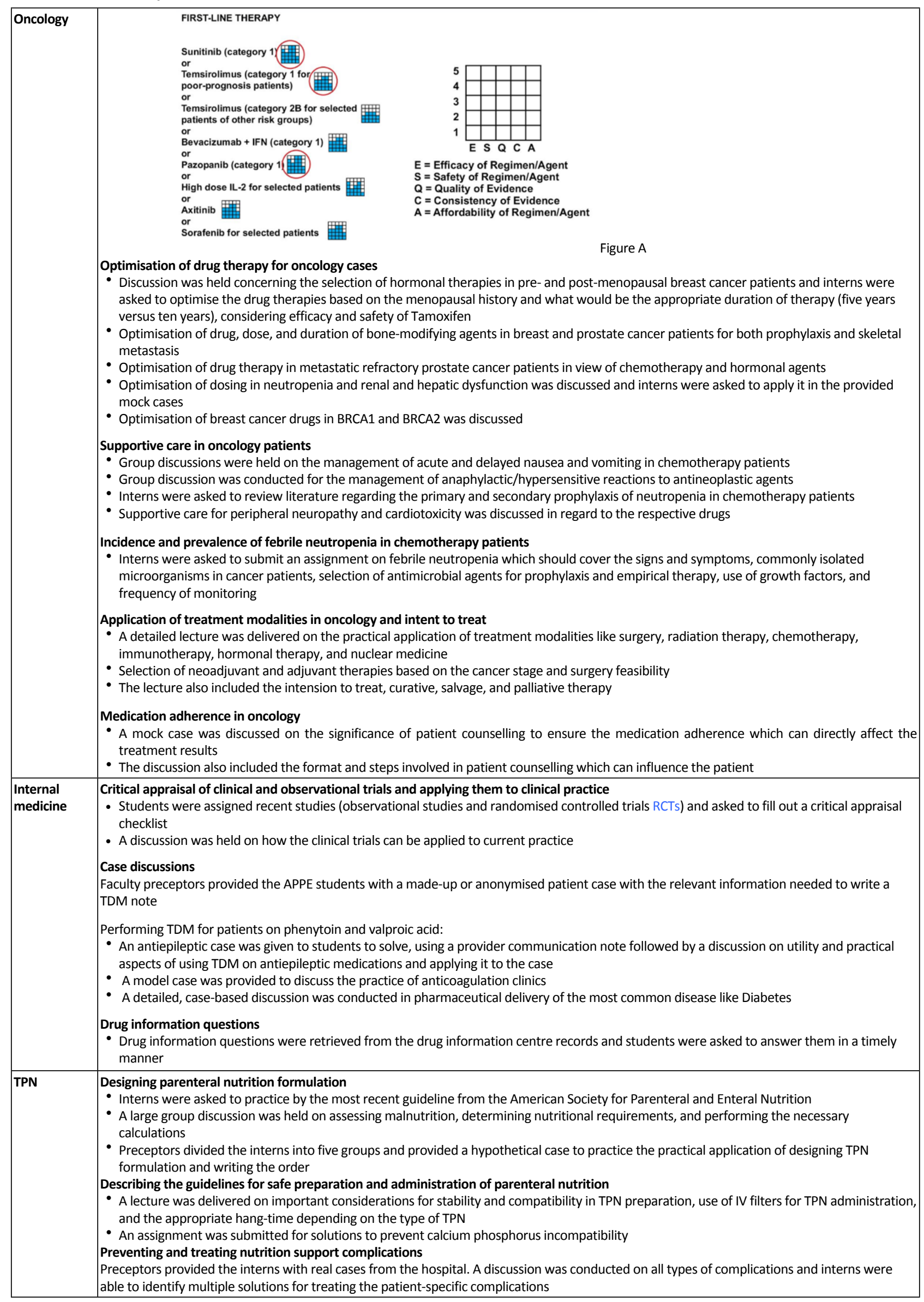




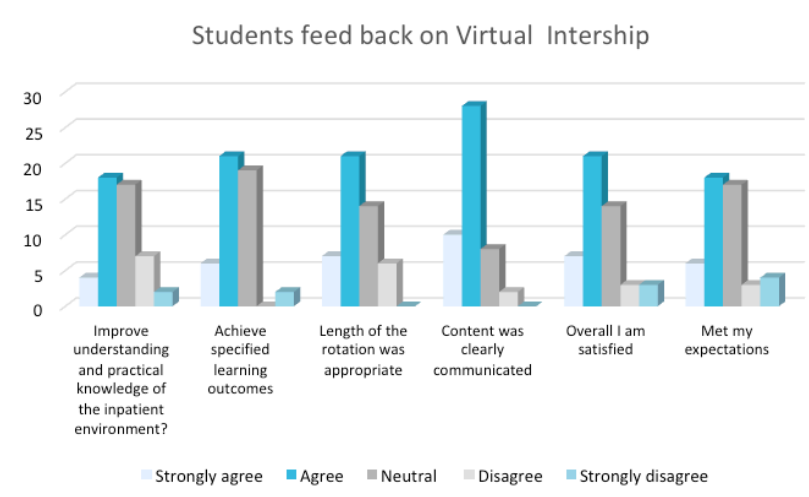

Figure B: Interns' feedback

Overall, the learners' feedback indicates that the redesign, content, and mode of delivery met their learning needs. More than half of the survey participants agreed that the redesigned APPE rotations helped them to understand the content and achieve the learning outcomes. Therefore, they suggested this may be considered as a learning strategy in case of a similar emergency situation in future. However, they also emphasised that virtual internships cannot replace onsite training. Open-ended questions in the feedback survey indicated that interns generally perceive that the redesigned APPE rotation benefitted their practice experience in some ways. Students noted the following:

- 'Expecting that it will be really a boring lecturing internship repetition of what we learn in the theory: BUT IT WAS NOT'

- 'I love the idea of simulated patient more than the simulated videos'

- I'm happy that we are learning ourselves and preceptor filling the gaps'

- I wish we could also do more simulated evens that might happen during ward rounds or patient education'

- 'Excellent and effective training, but I prefer if the class timings were regular, instead of having morning and evening classes'

\section{Discussion}

In this study, the authors presented the experience of faculty preceptors in transforming the APPE student experience into virtual platforms, in response to a global pandemic. In hospital or clinical pharmacy experiences, students are expected to apply their knowledge and skills in patient care activities (Kahaleh \& Murphy, 2005). Due to the infection risk of hospital pharmacy placements during the novel COVID-19 pandemic, innovating new modalities of these experiences was required.

It has been well documented in the literature that the use of videoconferencing is a useful educational modality in clinical sciences (Augestad \& Lindsetmo, 2009; Stain et al., 2005). It is also reported that videoconference sessions of APPE rotation were effective and successful. Similarly, preceptors, college administrators, and interns believe that the video conference offers a better experience to students in the absence of real experience of clinical settings (Eiland et al., 2018). Additionally, it is stated that online virtual patient cases and self-paced online transition modules are effective for pharmacy education (Al-Dahir et al., 2014; Tchen et al., 2018). Ohinmaa et al. (2002) reported that, compared to conventional methods, video conferences are also cost-effective. Therefore, the authors believe that virtual APPEs are an appropriate solution for providing a simulated pharmacy practice experience.

During these unprecedented times, many pharmacy schools are using innovative methods to provide students with experiential education (Kawaguchi-Suzuki et al., 2020). Some pharmacy schools have published their administrative and operational experience (Draugalis et al., 2020). Internationally, several other institutions have documented their altered educational modalities (Fuller et al., 2020; Lyons et al., 2020). Locally, other pharmacy colleges in Saudi Arabia have documented their transformation into a virtual mode (Badreldin et al., 2020). Hopefully, these learned lessons will provide the pharmacy education community with guidance to facilitate developing disaster management plans and adapting their programmes to more flexible models.

\section{Limitations}

This is a single-institution experience. Also, due to the sudden nature of the pandemic and its lockdown measures, the authors had limited time to plan their restructuring modalities. In addition, they had limited staff participating in their restructuring experience as the hospital and practice partners were having maximum capacity on the frontlines of the COVID-19 pandemic.

\section{Conclusion}

This paper presents redesigned APPE training of one of the top universities in Saudi Arabia. The authors highlighted the various restructuring modalities and 
learning methods used for different clinical rotations to achieve the learning outcomes in remote learning situations. The authors firmly believe that this paper may guide other institutions in similar circumstances in the future.

\section{Acknowledgements}

The authors sincerely thank the Dean College of Clinical Pharmacy, Vice-Dean Academic Affairs, all the preceptors and teaching assistance of the pharmacy practice department. Further, they openly thank the dedicated interns, for making the virtual internship experience more feasible and successful.

\section{References}

Al-Dahir, S., Bryant, K., Kennedy, K.B., \& Robinson, D.S. (2014). Online virtual-patient cases versus traditional problem-based learning in advanced pharmacy practice experiences. American Journal of Pharmaceutical Education, 78(4), 76. https://doi.org/ $\underline{10.5688 / a j p e 78476}$

Almaghaslah, D., Alsayari, A., Asiri, R., \& Albugami, N. (2019). Pharmacy workforce in Saudi Arabia: Challenges and opportunities: A cross-sectional study. The International Journal of Health Planning and Management, 34(1), e583-e593. https://doi.org/10.1002/hpm.2674

AlRuthia, Y., Alsenaidy, M.A., Alrabiah, H.K., AlMuhaisen, A., \& Alshehri, M. (2018). The status of licensed pharmacy workforce in Saudi Arabia: a 2030 economic vision perspective. Human Resources for Health, 16(1), 28. https://doi.org/10.1186/ $\underline{\text { s12960-018-0294-8 }}$

American Council for Pharmacy Education. (2016). Accreditation Standards and key elements for the professional program in pharmacy leading to the Doctore of Pharmacy degree. Accreditation Council for Pharmacy Education Chicago, Illinois. (online). Available at: https://www.acpe-accredit.org/pdf/ Standards2016FINAL.pdf

Asiri, Y.A. (2011). Emerging frontiers of pharmacy education in Saudi Arabia: The metamorphosis in the last fifty years. Saudi Pharmaceutical Journal, 19(1), 1-8. https://doi.org/https:// doi.org/10.1016/i.jsps.2010.10.006

Augestad, K.M., \& Lindsetmo, R.O. (2009). Overcoming Distance: Video-Conferencing as a Clinical and Educational Tool Among Surgeons. World Journal of Surgery, 33(7), 1356-1365. https://doi.org/10.1007/s00268-009-0036-0

Badreldin, H., Alshaya, O., Saleh, K., \& Alshaya, A. (2020). Restructuring the Inpatient Advanced Pharmacy Practice Experience to Reduce the Risk of Contracting COVID-19: Lessons from Saudi Arabia. Journal of the American College of Clinical Pharmacy. https://doi.org/10.1002/jac5.1237

Barry, M., Al Amri, M., \& Memish, Z. (2020). COVID-19 in the Shadows of MERS-CoV in the Kingdom of Saudi Arabia. Journal of Epidemiology and Global Health, 10(1), 1-3. https://doi.org/10. 2991/jegh.k.200218.003
Dutton, J (2020). Coronavirus: Saudi Arabia closes schools and universities. 9th March 2020. The National News. Available at: https://www.thenationalnews.com/world/gcc/coronavirus-saudiarabia-closes-schools-and-universities-1.990002

Draugalis, J.R., Johnson, E.J., \& Urice, D.R. (2020). Challenges and Lessons Amid the COVID-19 Pandemic at One College of Pharmacy. American Journal of Pharmaceutical Education, 84(6), ajpe8157. https://doi.org/10.5688/ajpe8157

Dutta, A. (2005). The FPGEE curriculum requirement: An insurmountable hurdle? 1(69). Available at: https://www. researchgate.net/publication/294196593 The FPGEE curriculum requirement An insurmountable hurdle 1

Education \& Training Evaluation Commission. (2018). Standards For Program Accreditation. National Commission for Academic Accreditation \& Assessment. Available at: https://etec.gov.sa/ en/productsandservices/NCAAA/AccreditationProgrammatic/Pag es/insprogdeve.aspx

Eiland, L.S., Staton, A.G., \& Stevenson, T.L. (2018). Providing an Academic APPE Elective via Videoconference Between Off-campus Faculty and Students. American Journal of Pharmaceutical Education, 82(8), 6645. https://doi.org/10.5688/ ajpe6645

Fuller, K.A., Heldenbrand, S.D., Smith, M.D., \& Malcom, D.R. (2020). A Paradigm Shift in US Experiential Pharmacy Education Accelerated by the COVID-19 Pandemic. American Journal of Pharmaceutical Education, 84(6), ajpe8149. https://doi.org/10. 5688/ajpe8149

IAU [Imam Abdulrahman Bin Faisal University]. (2020). College of Clinical Pharmacy homepage. Available at: https://www.iau.edu. sa/en/colleges/college-of-clinical-pharmacy

Kahaleh, A., \& Murphy, C. (2005). Ohio guidelines for advanced-practice hospital rotations for pharmacy students. American Journal of Health-System Pharmacy, 62(3), 246. https://doi.org/10.1093/ajhp/62.3.246

Kawaguchi-Suzuki, M., Nagai, N., Akonoghrere, R.O., \& Desborough, J.A. (2020). COVID-19 Pandemic Challenges and Lessons Learned by Pharmacy Educators Around the Globe. American Journal of Pharmaceutical Education, ajpe8197. https://doi.org/10.5688/ajpe8197

Lyons, K.M., Christopoulos, A., \& Brock, T.P. (2020). Sustainable Pharmacy Education in the Time of COVID-19. American Journal of Pharmaceutical Education, 84(6), ajpe8088. https://doi.org/ $\underline{10.5688 / a j p e 8088}$

Ohinmaa, A., Vuolio, S., Haukipuro, K., \& Winblad, I. (2002). A cost-minimization analysis of orthopaedic consultations using videoconferencing in comparison with conventional consulting. Journal of Telemedicine and Telecare, 8(5), 283-289. https://doi. org/10.1177/1357633X0200800507

Stain, S.C., Mitchell, M., Belue, R., Mosley, V., Wherry, S., Adams, C.Z., Lomis, K., \& Williams, P.C. (2005). Objective assessment of videoconferenced lectures in a surgical clerkship. American Journal of Surgery, 189(1), 81-84. https://doi.org/10.1016/ j.amjsurg..2004.04.012

Tchen, P., Leung, L., Simpson, F., Kim-Sing, A., \& Pearson, M. (2018). Bridging the gap: An evaluation of self-paced online transition modules for advanced pharmacy practice experience students. Currents in Pharmacy Teaching and Learning, 10. https://doi.org/10.1016/i.cptl.2018.07.006 